\title{
MOVING OUT OF OLDENBURG'S LONG SHADOW: WHAT IS THE FUTURE FOR
} SOCIETY PUBLISHING?

\author{
Chris Armbruster \\ Research Associate, Max Planck Digital Library, \\ Max Planck Society \\ Invalidenstrasse 35, D 10115 Berlin \\ www.mpdl.mpg.de \\ Executive Director, Research Network 1989 \\ www.cee-socialscience.net/1989
}

Accepted for publication

Learned Publishing, 20, 259-266

doi: $10.1087 / 095315107 X 239627$

\begin{abstract}
The internet and the rise of e-Science alter the conditions for scholarly communication. In signing declarations against open access mandates, society publishers indicate that they feel most threatened by the emergence of institutional repositories and the self-archiving mandates that these make possible. More attention should be paid to the impact of e-Science, the rise of internet-based guild publishers and the entrance of players from the new economy. Society journals should stop aspiring to such functions as registration and archiving and should shed electronic dissemination, while enhancing certification and investing in (new) navigation services.
\end{abstract}

\section{Keywords}

Scholarly Communication, Electronic Publishing, Society Publishing, Not-forprofit Publishing, Learned Societies, Professional Societies, Open Access, Institutional Repositories, Digital Libraries, Peer Review, Navigation Services 
Table of Contents

Moving out of Oldenburg's long shadow

The technology and economics of internet-based scholarly communication

The impact on societies

What is the role for mission-oriented publishers?

Faculty reluctance?

Shifting from 'content' to 'service'

\section{Acknowledgements}

Crispin Taylor provided invaluable feedback from the perspective of a society publisher (American Society of Plant Biologists). The Max Planck Digital Library, and its director, Laurent Romary, provided a base from which to develop ideas on the future of academic publishing. The opinions and errors are mine. 


\section{Moving out of Oldenburg's long shadow}

In the Philosophical Transactions, Henry Oldenburg in 1665 provided the model of academic journal publishing, conjoining dissemination and certification, and setting up the journal as a register and archive of knowledge claims. With the internet, however, the time has come to step out of Oldenburg's long shadow. As publishers, learned and professional societies have done exceptionally well in applying their knowledge networks and tools to produce outstanding journals. They stand to benefit from open access because society publishers are embedded within their specific community, which they serve in a number of ways. They are ideally placed to utilise the rise of digital peer production (e.g. e-Science, but also the textgrid for the humanities) and global epistemic networks (researchers sharing a broadly defined research programme and, for example, sharing pre-prints) to deliver value-adding services to a global audience of users. Society publishers may find that institutional repositories and, more generally, digital libraries, could become partners in publishing. If repositories and libraries collect, disseminate and curate the content, then society publishers may concentrate on providing what they do best: adding value through certification and navigation services.

A number of services exemplify a shift by which globally distributed peers in a given field can utilise digital technologies to collaborate in providing services for their community in the spirit of open science. Some are already of global scope, such as arXivi and Research Papers in Economics (RePEc) ${ }^{i i}$; others are of narrower scope but still of global reach through open access, such as Math-Netiii or archives pertaining to European integration (e.g. European Research Papers Archive ${ }^{\text {iv }}$ and Archive of European Integration). ${ }^{v}$ I would characterise these as 'guild publishers'.

Society publishers will need to find ways of relating to the new internetbased guild publishers and the digital repositories they rely on - be it to determine the scope for mutual learning and co-operation or to delineate the potential for competition. To date, the relationship is largely complementary because guild publishers usually disseminate only working papers and preprints. Moreover, many are supported by institutional subsidies and volunteer effort and are not commercial ventures in their own right. The notable exception is the Social Science Research Network (SSRN) ${ }^{\mathrm{vi}}$, which is commercially selfsustaining through advertising. However, most global guild publishers are built on research active communities and editorial services as well as featuring some form of certification (quality indicators, even peer review) and navigation services (search, review, ranking). Global guild publishers are becoming pervasive across an increasing number of disciplines and SSRN is launching a service to cover the humanities. In this sense, global guild publishers are embryonic societies that could opt to build commercially viable alternatives to society publishers.

The following argument on how society publishers should reappraise their function as publisher derives from an ongoing investigation into how open 
science is compatible with the knowledge-based economy if markets are based on nonexclusive rights. ${ }^{\text {viviii }}$ In particular, I am concerned with how the publishing of research articles and data may be open and profitable, while enabling the enhancement of certification services (e.g. consider the post-publication peer review provided by Faculty of $1000^{\text {ix }}$ or the interactive and inclusive peer review of Atmospheric Chemistry and Physics ${ }^{\mathrm{x}}$ ), seamlessly integrated navigation services (e.g. as provided by the Living Reviews journal family ${ }^{\mathrm{xi}}$ ) and new forms of overlay services such as text mining (e.g. the National Centre for Text Mining $\left.(\mathrm{UK})^{\mathrm{xi}}\right)$. In this context, I have argued that pressure for the duplication of research articles in OA repositories (the 'green road') is misguided because of the extra expense, the problem of version control and too much variation in deposit mandate policies; and that OA publishing (the 'gold road') has no future outside biomedicine because author charges of $\$ 1500, \$ 2500$ and more presuppose large research budgets and in most other disciplines preprints provide cost-effective alternative to ensure global inclusion in scholarly communication (see below).

\section{The technology and economics of internet-based scholarly communication}

In the context of the knowledge-based economy, e-Science and digital repositories provide the impetus for academic journal publishing to move out of Oldenburg's long shadow ${ }^{\text {xiii }}$. The rise of the internet has a number of consequences:

- While in the print world printing and distribution were costly and peer review added considerable value, in the internet world the cost ratio is inverted: dissemination is cheap and peer review increasingly expensive in that demand on qualified reviewers is multiplying as more is written and peer review is extended as such (e.g. to research assessment exercises or the admission of graduate students). The internet favours the separation of dissemination from certification. Moreover, the need for more elaborate forms of certification will be reinforced by the continuing global expansion of higher education and research.

- E-Science and related developments make open access to research publications and data intrinsically desirable for the future advancement of knowledge. This favours the public registration of knowledge claims and open archiving.

- The knowledge-based society thrives on the (commercial) re-use of research, creating a case for treating research results as information in the R\&D pipeline as well as making commercial re-use of research articles and data desirable. For that to happen, research results and data must be made available on the basis of a nonexclusive license, so that a multitude of service providers may target wider and new audiences, particularly in the knowledge-intensive industries and services.

In effect, 'content holding' is a shrinking business model. This is so, because the resulting toll access to content reduces inclusion and impact in scholarly communication, hinders the progress of e-Science and stifles commercial and 
non-commercial re-use which could benefit readers in knowledge-based industries, government and higher education. ${ }^{\text {xiv }}$ Moreover, content-holding publishers tend to increase their costs by striving to fulfil too many functions (from registration through to archiving). Given the cost-effective alternative of electronic dissemination through repositories, there is a strong argument against content holding by publishers.

Society publishers have typically understood themselves to be driven by the mission of aiding scholarly communication and enhancing the dissemination of knowledge. Although the transition to internet-based publishing may cause anxiety as the Oldenburg model disintegrates, societies should welcome the enhanced opportunities for access, inclusion and impact. As a communityembedded service provider, the society publisher need neither fear the squeeze of the big deals between publishers and libraries nor worry unduly about a dilemma between restricting access through subscription charges and suffering economic hardship through open access. ${ }^{x v, x v i}$ To fully appreciate the new opportunities, I would suggest that societies switch their perspective as publishers from one of 'content holding' to the provision of certification and navigation services.

\section{The impact on societies}

The scholarly journal is peer-produced in that authors, readers, editors and reviewers are usually peers. Societies typically bring together communities. However, the internet adds a digital dimension and enables global communities to collaborate in real time. The new global guild publishers typically:

- Bring together global epistemic communities, that is those researchers around the world who share a broadly defined research programme (e.g. high-energy physics, neo-classical economics, or - more narrowly focused quantitative biology, management research) and are thus not only readers but also potentially authors, including authors in applied contexts (e.g. economists working for banks).

- Rely on digital peer production, not only asking authors to provide the research articles and some metadata, but also providing editorial services that make visible and push out content as well as supplying metrics that serve to indicate quality, usage and impact (e.g. all larger guild publishers offer rankings and some do citation counts, including a recursive weighting that factors in the impact of the citing article).

In utilising internet technology to slash costs, guild publishers have become the guardians of the scientific knowledge commons. Where commercial publishers struggle to enhance access to research articles, and fail because of escalating costs and rising prices (whatever their business model), guild publishers prevail in guaranteeing equal and open access. In dealing with the internet, societies need to appreciate the opportunities and constraints associated with digital technologies and recognise that, for societies, the new digital players could be partners in open access mode, but would be competitors if societies seek to be exclusive content holders ${ }^{\text {xvii }}$. 
The American Council of Learned Societies' (ACLS) Commission on Cyberinfrastructure for Humanities and Social Sciences distinguished a technical from an enabling cyberinfrastructure. ${ }^{\text {xviii }}$ In the category of technical infrastructure the commission placed transport (e.g. broadband), devices (e.g. components, standardization), transmission protocols (e.g. TCP/IP) and software. By 'enabling infrastructure' they meant standards of interoperability, intellectual property rights, privacy laws, and institutional policies within the academy. The ACLS commission assumed that the technical layer was neutral and in this sense unproblematic, and focussed on law and policy. However, it missed the crucial distinction between the 'physical' (transport, devices) and the 'logical' (transmission protocols, software). ${ }^{\text {xvii }}$ It is the logical layer that represents the material condition of production for e-Science. It conditions what scientists and scholars can and cannot do in creating and in distributing knowledge. Insofar as the logical layer is open, and open middleware and open source software predominate in e-Science ${ }^{\mathrm{xix}}$, this favours open content.

The ACLS commission worried about copyright. If one assumes that any scholarly text is a property to which somebody holds exclusive rights, then the 'digital dilemma' equally applies to scholarly publishing. The US National Academies' Committee on Intellectual Property Rights and the Emerging Information Infrastructure outlined the assumed digital dilemma succinctly: what 'if the entire market can be extinguished by the sale of the first electronic copy? ${ }^{\prime x x}$ However, there is no digital dilemma surrounding science, as authors typically give away their first copy. ${ }^{\text {xi }}$ When societies conceive of their publishing as a business analogous to music or film, they have forgotten what science is all about: ${ }^{x \times i}$

The substantive findings of science are a product of social collaboration and are assigned to the community. They constitute a common heritage in which the equity of the individual producer is severely limited. An eponymous law or theory does not enter into the exclusive possession of the discoverer and heirs, nor do the mores bestow upon them special rights of use and disposition. Property rights in science are whittled down to the bare minimum by the rationale of the scientific ethic. The scientist's claim to 'his' intellectual 'property' is limited to that of recognition and esteem which, if the institution functions with a modicum of efficiency, are roughly commensurate with the significance of the increments brought to the common fund of knowledge.

In summary, guild publishers provide dissemination and basic quality indicators as a peer-produced service, which is free to both authors and readers. Projects to scan and make searchable the contents of books are equally premised on being free to contributors and readers. Costs are recuperated without holding exclusive rights to the content. Insofar as societies concentrate on 'open access' as threat, they miss the broader shift towards openness in e-Science and e-Publishing. 


\section{What is the role for mission-oriented publishers?}

It has been said that mission-orientation makes not-for-profit publishers special. ${ }^{x \text { iii }}$ They have a special relationship with authors and readers and ultimately disseminate information to serve their communities and advance knowledge. Thus I would argue that locking up content means defaulting on the society's mission. If the current society publishing model is a means to a mission-driven end, then there should be no inherent obstacle to re-assessing the function and financing of the journal.

Mark Ware has recapitulated the functions of the journal as registration, dissemination, peer review and archival record, tentatively adding navigation as a fifth function. ${ }^{\text {xiv }}$ Ware's list corresponds closely to the functions of scholarly communication identified by Herbert van de Sompel and colleagues, namely registration, certification, awareness, archiving and rewarding. ${ }^{\mathrm{x} v}$ The latter, however, were not looking at traditional journals but at the first global epistemic guild publisher, arXiv.

ArXiv and, by implication, digital repositories and libraries more generally, provide the means whereby registration, dissemination and archiving may be organised. Publishers that seek to maximise the rent obtainable from holding exclusive content will object, but mission-oriented publishers have every reason to ask if they could not shed costs and enhance their mission if they collaborated with repositories, concentrating on the functions repositories cannot offer: certification and navigation services.

\section{$\underline{\text { Registration }}$}

The idea of a journal as registrar of knowledge claims has always been flawed if the journal rejects submissions, for then authors' knowledge claims initially would exist only in a 'limbo' of rejection and resubmission until acceptance. The preferable digital solution is public registration in a repository as any deposit would be immediate and independent of any intermediary. Incidentally, a direct and open deposit also better protects the author's moral rights - including claims to priority and against plagiarisers as well as protection against the lifting of ideas from 'not yet published' texts, which is particularly important for younger authors.

\section{Archiving}

A journal has only ever been an archive for the initially published version. In many fields subsequent modification and re-issue of an article has not been uncommon, especially of those articles that are considered groundbreaking. Archiving is ultimately the function of libraries. If society publishers assume the function of internet archiving, they have to worry about retrodigitisation of print material and the maintenance of archives, as well as facing potentially large future financial risks due to the obsolescence of current technology. The ageold tradition of the deposit library may be revitalised by designating digital deposit libraries. 


\section{Dissemination}

In the print world the printed journal was the premier vehicle for dissemination. Industry experts judge first copy costs, on average, to be $\$ 3,500-4,000$. xxiv,xxvi OA author-side charges, where raised by the publisher, tend to range between $\$ 1,500-3,000$ (i.e. the range from BMC to PLoS and Springer); this would imply that if the first copy is produced in-house in the traditional way, costs remain substantial. An informal enquiry with some of the major guild publishers yielded an average 'first copy cost' below $\$ 5$ for preprints and post-prints posted by the author and pushed out through editorial services. vii Guild publishers certainly do not, for this sum, provide as extensive editorial services as trade publishers do, but if, upon enquiry, arXiv, RePEc and SSRN all say that their equivalent 'first copy costs' would be below $\$ 5$, this indicates, even if allowing for a large margin of error, that traditional publishers have not examined their business model sufficiently critically, which makes them vulnerable to new competitors.

These advantages of repositories indicate that research articles (as preprint and published version) as well as data are best routinely deposited in and disseminated from repositories. This is congruent with the norms of science, is cost-effective, simplifies version control (preprint and published version only) ${ }^{x x v i i}$, maximises access, inclusion and impact in scholarly communication and opens up the commercial re-use of scientific information.

Societies embedded in a research community should be able to provide superior services for the cluster of functions designated variously as certification, peer review, reward, navigation and awareness. These functions have always been congruent with the mission of learned and professional societies. Indeed, who would be better placed to organise certification, rewards and navigation than societies?

\section{Faculty reluctance?}

The above re-assessment of functions suggests that adaptation to the digital environment is desirable. However, the Andrew W. Mellon Foundation has disbursed a large grant to the Center for Studies in Higher Education at UC Berkeley on the hypothesis that

approaches that try to 'move' faculty and deeply embedded value systems directly towards new forms of archival, 'final' publication are destined largely to failure in the short-term. ${ }^{\text {xviii }}$

A planning study has been conducted at UC Berkeley, including in-depth interviews with faculty, editors, librarians and administrators across five disciplines from the sciences to the humanities. ${ }^{\text {xix }}$ Close scrutiny of the results reveals, however, an unacknowledged shift in academic practice from 'norms' to 'interests', from scholarly community to institutional hierarchies. Consider these two incongruencies:

1. The respondents and the authors of the study insist that peer review is the hallmark of communication and publication, but the study reveals an 
increasing reliance on indirect and even surrogate measures of peer review (e.g. rank, funding or institutional affiliation of the author for the pre-print and the journal impact factor post-print) that substitute for the actual examination of argument and data;

2. The printed journal is preferred for the final archival publication while faculty demand and use electronic access and hardly ever consult the print edition any longer.

The planning study was undertaken at a prestigious university that has very structured career advancement. The story it tells is not one of a 'lack of willingness of faculty to change', but one of an 'unwillingness to take risks' in the face of an increasingly rigid academic stratification among institutions and within institutions. Authors seem to be afraid of doing anything that they think might even minimally diminish their chances of obtaining a tenure-track, principal investigator awards, a position at an even more prestigious university and so on.

The planning study hides the troubling evidence on stifled institutional innovation and risk-averse scholars by introducing a conceptual distinction between 'in-progress communication' and 'archival publication'. Experimentation and innovation will be confined to 'in-progress communication', so the study suggests, possibly only initially, possibly indefinitely. However, this conceptual distinction makes sense from the viewpoint of administrators and those concerned with rankings and selections. It makes no sense if science and scholarly communication are understood as an 'endless frontier'.

Societies and their members may be troubled by rigid institutional hierarchies and stifled innovation, but this should not lead them to misjudge the fundamental compatibility between the norms and economics of e-Science, open access and the knowledge-based economy.

\section{Shifting from 'content' to 'service'}

Societies should use their strategic advantage of being embedded in their research community to reconsider their function as publisher. This repositioning might suitably be undertaken as a shift from content to service.

We are in the midst of the transition to e-Science and internet-based scholarly communication. Providers will go on experimenting and build new services. While it is not possible to foresee the future, there are some innovations and emergent services in the area of certification and navigation which give an idea of what the road ahead will look like.

Some certification services, such as peer review of research papers and data, may well be appropriately funded by author-side charges. If the research funder wants the results to be openly accessible, or if the author wishes to retain all intellectual property rights, this makes sense. However, in most cases 
I would expect subscriptions and advertising to prevail as the predominant modes of funding.

Two examples of certification services that I believe have proven to work are the innovative form of transparent and inclusive peer review provided by Atmospheric Chemistry and Physics ${ }^{\mathrm{x}}$ and the post-publication peer review of Faculty of $1000 .^{\text {ix }}$

Atmospheric Chemistry and Physics is a not-for-profit e-journal published since 2001 by the European Geosciences Union (which has launched three more journals following the same interactive OA concept, and converted another). Submissions to the editor are rejected or accepted immediately, possibly with the help of peer review according to published criteria of significance, quality and presentation. Subject to technical corrections, initially accepted papers are published as discussion papers. This stage is designated as Atmospheric Chemistry and Physics Discussions (ACPD). Discussion papers are citable and available for public discussion. Referee comments, author comments and further comments from the community are interactive and viewable. After 8 weeks the public discussion closes and the authors are requested to revise the manuscript (if warranted) for a final decision on acceptance or rejection, possibly again with the help of peer review. For manuscripts in LaTeX, prepared according to technical instructions, ACP charges authors $€ 23$ per page (this charge may rise, for example, for a manuscript submitted in any LaTeX style to $€ 28$ and in any style, submitted electronically, to $€ 55$ per page). ACP deploys a Creative Commons Attribution - NonCommercial - ShareAlike License, which means that non-commercial copying and distribution is permitted while any alterations or transformations may only be undertaken if the subsequent work carries an identical license. The editors of $A C P$ insist that the initial check is rigorous, but that the open discussion would reveal any erroneous decision. However, the main function of the open discussion is to improve the quality of the paper while enabling the rapid dissemination of ideas and results. Moreover, contributions to the discussion themselves are archived and citable. ACP thereby gains the character of a logbook that records the advancement of knowledge claims, with due credit to reviewers and discussants.

BioMed Central's Faculty of 1000 functions as an online literature awareness tool. Biology, for example, is systematically covered in 18 faculties (from biochemistry to structural biology), which in turn comprise between 2 to 30 sections. Over 2300 internationally known faculty members have commented on over 35,000 articles. They provide readers with a continuously and rapidly evolving insider's evaluation of new research. A sister service in Medicine was launched in 2006. Faculty of 1000 is an institutional and individual subscription service. Individual subscriptions are priced at $\$ 116$. Subscribers may browse and search all papers by faculty and by section and sort them by various criteria such as date of publication, type of paper (novel finding, technical advance, interesting hypothesis, important confirmation, controversial finding) and 
number and strength of recommendations (recommended, must read, exceptional). Subscribers also have access to a 'Hidden Jewels' list of papers published in less-known journals, as well as alerting and rating services.

Two examples of valuable navigation services are the Living Reviews journal family ${ }^{\mathrm{xi}}$ and the LogEc service of RePEc. ${ }^{\mathrm{xx}}$ Living Reviews provides solicited online-only refereed review articles that guide active researchers at any stage of their career to the relevant literature. 'Living' review articles are updated regularly to incorporate the latest developments, seeking to advance the research programme. Articles are solicited by an international advisory board and are subjected to peer review. Authors update published articles regularly and the full history of any article (revisions, updates and errata) is viewable online. All review articles 'are readable online in HTML, integrated in a highly functional hypertext viewing environment. Sophisticated navigation support is offered for equations, figures, footnotes and references. Additionally, all references cited in Living Reviews articles are collated in online searchable literature databases, with the database entries linked back to and put into context by the annotation within the respective review articles'. The concept was pioneered as Living Reviews in Relativity by the Max Planck Institute for Gravitational Physics and has subsequently extended to Living Reviews in Solar Physics, Living Reviews in European Governance and Living Reviews in Landscape Research. Living Reviews is an open access service, with each journal being subsidised by its home institution. The software is available under a GNU Public Licence.

LogEc provides access statistics for RePEc ii. For economists it is a professional tool for tracking trends and usage; Citations in Economics (CitEc) is a parallel service for RePEc that tracks impact. Institutions (e.g. university departments, journal publishers) may participate by setting up a linked RePEc archive, which enables view and download counting as well as ranking for working paper series and journals. Prestigious research organisations and university departments are distributing their working papers series online, hence their tracking allows conclusions about emergent trends in the profession. The statistics are robust in that LogEc identifies and discounts for access by robots as well as discounting double access. Individual authors not participating through an institution may register independently with RePEc and thus subject their working papers and journal articles to LogEc, producing monthly updated statistics for top authors, articles and software items.

LogEc and Living Reviews give us a glimpse of the potential power inherent in open content for next-generation services in indexing, linking, mining and querying research publications and data. By ensuring the creation of wellpopulated repositories, deposit mandates will facilitate the emergence of these new overlay services. I suggest that societies should therefore consider engaging research funders and research organisations in discussion of how best to organise the deposition of publications and data in an open fashion, so that valuable new services may be developed by societies. 
inttp://arxiv.org/

ii http://repec.org/

iii http://www.math-net.de/

iv http://eiop.or.at/erpa/

v http://aei.pitt.edu/

vi http://www.ssrn.com/

vii Armbruster, C. 2007. Cyberscience and the Knowledge-based Economy, Open Access and Trade Publishing: From Contradiction to Compatibility with Nonexclusive Copyright Licensing. International Journal of Communications Law and Policy (in press). Working paper available at http://ssrn.com/abstract $=938119$

viii For a plea that societies should reconsider their publishing strategy, see Ch. 4 'Associations' and Ch. 6 'Cooperative' of Willinsky, J. The Access Principle. The Case for Open Access to Research and Scholarship. MIT Press 2005. Available at http://mitpress.mit.edu/catalog/item/default.asp?tid=10611\&ttype=2

${ }^{\mathrm{x}} \mathrm{http}: / / \mathrm{www} . \mathrm{f1000 \text {biology.com/ }}$

x http://www.copernicus.org/EGU/acp/

xi http://www.livingreviews.org/

xii http://www.nactem.ac.uk/

xiii Guédon, J-C. In Oldenburg's Long Shadow: Librarians, Research Scientists, Publishers, and the Control of Scientific Libraries. In Proceedings of the 138th ARL Membership Meeting.

Washington DC, Association of Research Libraries, 2001.

Available at http://www.arl.org/resources/pubs/mmproceedings/138mmproceedings.shtml

${ }^{x i v}$ Houghton, J and Sheehan, P. The Economic Impact of Enhanced Access to Research

Findings. CSES Working Paper 23, Melbourne, Centre for Strategic Economic Studies, 2006.

Available at http://www.cfses.com/documents/wp23.pdf

${ }^{\mathrm{xv}}$ Prosser, D. 2004. Between a rock and a hard place: the big squeeze for small publishers.

Learned Publishing 17: 17-22. http://dx.doi.org/10.1087/095315104322710214

${ }_{x v i}$ Gannon, F. 2005. Open access: scientists as paradoxical consumers. Learned Publishing 18, 295-9. http://dx.doi.org/10.1087/095315105774648870

xvii Consider how new economy firms have built their services on open source software because they identified this as the better solution and how old economy players, notably IBM, have followed suit in converting their business model. For a portrayal of the significance of these shifts, see Benkler, Y. The Wealth of Networks: How Social Production Transforms Markets and Freedom. New Haven, Yale University Press, 2006. Available at

http://www.benkler.org/wealth of networks/index.php/Download PDFs of the book

xviii Our Cultural Commonwealth: The final report of the American Council of Learned Societies Commission on Cyberinfrastructure for the Humanities \& Social Sciences. New York, American Council of Learned Societies, 2006. Available at http://www.acls.org/cyberinfrastructure/cyber.htm

${ }^{\mathrm{xix}}$ For example, the Open Middleware Infrastructure Institute UK, run by the UK e-Science programme. http://www.omii.ac.uk/

${ }^{x \times}$ The Digital Dilemma: Intellectual Property in the Information Age. Washington DC, National Academy Press, 2000. Available at http://newton.nap.edu/html/digital dilemmal

${ }^{x \times i}$ Frankel, M. Seizing the Moment: Scientists' Authorship Rights in the Digital Age.

Washington DC, American Association for the Advancement of Science, 2002. Available at http://www.aaas.org/spp/sfrl/projects/epub/finalrept.html

$\mathrm{xxii}$ Merton, R. 1942. Science and Technology in a Democratic Order. Journal of Legal and Political Sociology, 1: 115-26.

xxiii Morris, S. 2001. What's so special about not-for-profit publishers? Learned Publishing 14:

163-5. http://dx.doi.org/10.1087/095315101750240403

${ }^{x x i v}$ Ware, M. Scientific publishing in transition: an overview of current developments.

ALPSP/STM White Paper. Worthing, Association of Learned and Professional Society

Publishers, 2006. Available at http://www.alpsp.org/ForceDownload.asp?id=127 
${ }^{x x v}$ Sompel, H. van de et al. 2004. Rethinking Scholarly Communication: Building the System that Scholars Deserve. D-Lib Magazine 10: 9. Available at http://www.dlib.org/dlib/september04/vandesompel/09vandesompel.html

${ }_{\mathrm{xxvi}}$ For a more elaborate scenario and idealised calculations see King, D. 2007. The Cost of Journal Publishing: a literature review and commentary. Learned Publishing 20: 85-106. http://dx.doi.org/10.1087/174148507X183551

xxvii Harley, D et al. The Influence of Academic Values on Scholarly Publication and Communication Practices, Research \& Occasional Paper Series. Berkeley, Center for Studies in Higher Education, 2006. Available at Antelman, K. 2006. Self-archiving practice and the influence of publishers' policies in the social sciences. Learned Publishing 19: 85-95. http://dx.doi.org/10.1087/095315106776387011

xxviii Harley, D et al. The Influence of Academic Values on Scholarly Publication and Communication Practices, Research \& Occasional Paper Series. Berkeley, Center for Studies in Higher Education, 2006. Available at http://cshe. berkeley.edu/publications/publications. php?id=260

${ }^{x x i x}$ King, C et al. Scholarly Communication: Academic Values and Sustainable Models. Report on a Planning Study. Berkeley, Center for Studies in Higher Education, 2006. Available at http://cshe.berkeley.edu/publications/publications.php?id=23

${ }^{30}$ http://logec.repec.org/ 